\title{
Health as a Complex Adaptive System: a new dimension of patient care in internal medicine and general practice
} [version 1; peer review: 1 approved, 1 approved with

\section{reservations]}

\author{
Johannes Bircher1, Eckhart G. Hahn² \\ ${ }^{1}$ Department of Hepatology, University of Bern, Meikirch, CH-3045, Switzerland \\ ${ }^{2}$ Department of Medicine 1, University Hospital Erlangen, Erlangen, D-91054, Germany
}

\section{V1 First published: $12 \mathrm{Jul}$ 2016, 5:1672 \\ https://doi.org/10.12688/f1000research.9042.1}

Latest published: 16 Sep 2016, 5:1672

https://doi.org/10.12688/f1000research.9042.2

\section{Abstract}

This paper explores the diagnostic and therapeutic potential of a new concept of health. Investigations into the nature of health have led to a new definition that explains health as a complex adaptive system (CAS) and is based on five components (a-e). Humans like all biological creatures must satisfactorily respond to (a) the demands of life. For this purpose they need (b) a biologically given potential (BGP) and (c) a personally acquired potential (PAP). These properties of individuals are embedded within (d) social and (e) environmental determinants of health. Between these five components of health there are 10 complex interactions that justify health to be viewed as a CAS. In each patient, the current state of his health as a CAS evolved from the past, will move forward to a new future, and has to be analyzed and treated as an autonomous whole. A diagnostic procedure is suggested as follows: together with the patient, the five components and 10 complex interactions are assessed. This may help the patient to better understand his situation and to recognize possible next steps that may be useful for him to evolve toward more health by himself. In this process mutual trust in the patient-physician interaction is critical. The described approach offers new possibilities to help patients to improve their health.

\section{Keywords}

Meikirch model, health , complex adaptive system , primary care , internal medicine, family medicine, diagnosis, therapy

\section{Open Peer Review \\ Approval Status \\ $\checkmark v$ \\ 1 \\ 2 \\ version 2 \\ (revision) \\ 16 Sep 2016 \\ version 1 \\ 12 Jul 2016

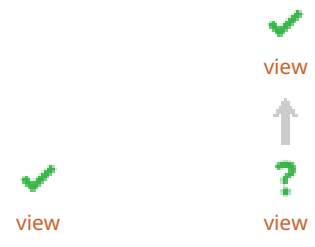 \\ 1. Joachim P Sturmberg (iD, University of Newcastle, Wamberal, Australia \\ 2. Dianne Delva, University of Ottawa, Ottawa, \\ Canada}

Any reports and responses or comments on the article can be found at the end of the article. 
Corresponding author: Eckhart G. Hahn (eckhart.hahn@uk-erlangen.de)

Competing interests: No competing interests were disclosed.

Grant information: The author(s) declared that no grants were involved in supporting this work.

Copyright: $\odot 2016$ Bircher J and Hahn EG. This is an open access article distributed under the terms of the Creative Commons Attribution License, which permits unrestricted use, distribution, and reproduction in any medium, provided the original work is properly cited.

How to cite this article: Bircher J and Hahn EG. Health as a Complex Adaptive System: a new dimension of patient care in internal medicine and general practice [version 1; peer review: 1 approved, 1 approved with reservations] F1000Research 2016, 5:1672 https://doi.org/10.12688/f1000research.9042.1

First published: 12 Jul 2016, 5:1672 https://doi.org/10.12688/f1000research.9042.1 


\section{Introduction}

Citizens consult their physicians when they feel that something is not in order, e.g. when they experience pain, fatigue or any other disorder. Physicians then examine them and specifically look for pathological changes. After investigation they make a provisional diagnosis and explore their patients further or treat them accordingly. This type of thinking goes back to the pathologist Rudolf Virchow, who in 1858 used 20 lectures to describe "cellular pathology", a characterization of different diseases ${ }^{1}$. Although the foundations of medicine have vastly changed since then, the general principles of medical practice have remained the same. Only over the past 20 years, complexity science has gradually entered into medicine ${ }^{2,3}$. This has become particularly important for the interpretation of health and disease as different states of a complex adaptive system (CAS). The Meikirch model is a new definition of health that exhibits all the features of a $\mathrm{CAS}^{4}$. For such systems the concepts based on Virchow's pathology are no longer appropriate. An understanding of health and disease now requires appreciation of complexity science. It introduces a new dimension for diagnosing and treating patients. It includes the potential to improve health in a way that hitherto was practiced only exceptionally. The purpose of this paper is to summarize the relevant features of the Meikirch model and to reveal in detail how the model and complexity science may be applied for a better understanding of a patient's disease and for its treatment.

\section{The Meikirch model: definition of health and disease}

The Meikirch model is based on five components (Box 1) and 10 complex interactions (Figure 1). This framework allows to define health and disease as a complex adaptive system (Box 2). Figure 1 depicts the five components from $a$ to $e$. The interactions are exhibited as double-edged arrows from $1-10$. A short explanation of the five components and their interactions is presented below. The complete description of the model with its scientific background is given in the original publications ${ }^{4,5}$.

Box 1. Meikirch model: The five interacting components of health ${ }^{4,5}$
a. Life's demands (LD)
b. Biologically given potential (BGP)
c. Personally acquired potential (PAP)
d. Social determinants (SD)
e. Environmental determinants (ED)

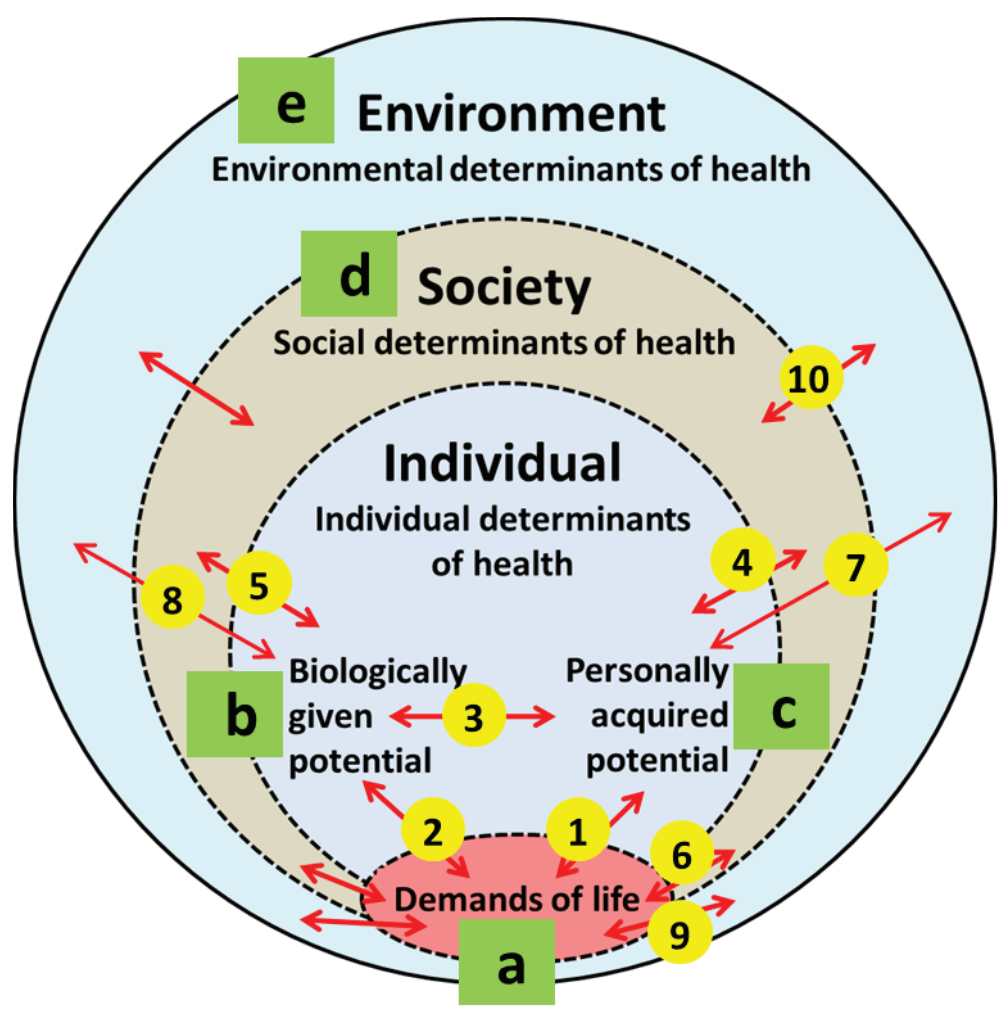

Figure 1. The Meikirch model consists of five components (a-e) and ten complex interactions (1-10). 
Box 2. Wording of the Meikirch model i.e. the definition of health and disease ${ }^{4,5}$

1. Health is a dynamic state of wellbeing emergent from conducive interactions between an individual's potentials, life's demands, and social and environmental determinants.

2. Health results throughout the life course when an individual's potentials and social and environmental determinants suffice to respond satisfactorily to the demands of life. Life's demands can be physiological, psychosocial, or environmental, and vary across individuals and contexts, but in every case unsatisfactory responses lead to disease.

Each human must fulfil his demands of lif $\boldsymbol{e}^{6}$. Physiological, psychosocial and environmental demands vary with time and circumstances. Physiological demands are related to the homeokinetic balance of nutrients, energy and water to maintain bodily functions including procreation; examples are work, pregnancy, childbirth and brain function. Psychosocial demands are the individual's exposure and response to social conditions to succeed in social integration and mental, personal and spiritual development. Expectations and roles related to work, family and society as a whole combine with personal aspirations, values and lifestyle in changing settings and contexts. This includes also peace with the fact, that every human being must die. Environmental demands include availability and immediate or latent threats from living conditions (e.g. water, nutrients, climate, radioactivity, pollutants, carcinogens, workplace conditions).

The potential of an individual to meet his demands of life is partly biological e.g. a gift by nature - biologically given potential (BGP) - and partly acquired during life - personally acquired potential (PAP). At the time of birth the BGP is based on the genetic equipment, epigenetic regulation and quality of the pregnancy. The BGP diminishes throughout life and is zero at the time of death. During lifetime the BGP may be threatened or damaged by socioeconomic disadvantages, diseases, injuries and defects. The PAP results from the entirety of physiological, mental, spiritual and social resources acquired during lifetime. It may continue to grow when a person cares for it. Social and environmental conditions also influence the growth of the PAP by providing or withholding determinants of health.

Social determinants of health strongly interact with the demands of life and the potentials of the individual ${ }^{4}$. Equity and equality, social concerns, working conditions, autonomy and social participation affect health and longevity ${ }^{7,8}$ and are major determinants of health. Likewise, environmental determinants of health are factors in living and working conditions affecting each person. They may sometimes be of global significance like natural resources, population growth and climate change $e^{9,10}$.
Based on these five components and their interactions with each other the Meikirch model represents a new definition of health and disease as shown in Box 2. Possible outcomes on individual and public health care as a result of a hypothetical implementation of the Meikirch model have been discussed elsewhere and suggestions for clinical and health systems research have been made ${ }^{5}$.

\section{Health as a Complex Adaptive System (CAS)}

A complex adaptive system is an entity with a more or less permeable boundary between it and its nearby environment (Figure 2) ${ }^{11}$. It can take up material and energy from the environment (input), release end products (output, e.g. entropy) and do work. Within the system there are many different parts called agents. In Figure 2 they are symbolized as circles. They continuously and autonomously interact with each other in a nonlinear manner, contributing to the product, the so called emergence of the CAS. The term emergence indicates a new and often unpredictable quality which is more than the sum of the functions of each part. A CAS always functions as a whole. Attractors are sites to which the energy flow of the system may be drawn. A CAS is equipped with a learning and bonus arrangement for the interactions among its agents. This gives it the possibility to adapt to changes in the environment, i.e. to learn. If for some reason this adaptation functions poorly, the CAS suffers. If it does not function at all the CAS becomes chaotic and goes into a crisis or vanishes. Repeated critical disturbances may lead to the so called butterfly effect ${ }^{2}$. Examples of medical conditions are ventricular fibrillation, epileptic seizures, tantrum, or psychotic states. Every CAS has evolved from a prior condition and autonomously progresses toward an unforeseeable future state. A CAS may be part of a larger CAS or be composed of many CASs. Such structures are called nested CASs.

In the Meikirch model the five components (a-e) including their subcomponents are regarded as agents (Figure 1). Interacting with

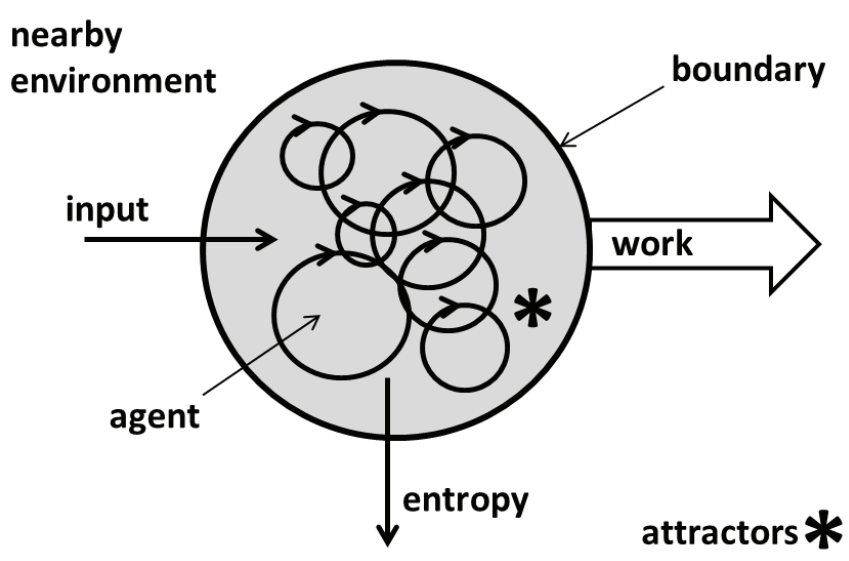

Figure 2. General model of a complex adaptive system (CAS). 
each other they spontaneously arrange themselves in such a way that the evolving emergence, i.e. the state of health, is the result of the functioning of the system as a whole. In each case a specific working-arrangement is operational, but it is not necessarily the best solution for the system. Energy flow in humans has been called vitality, drive, or sense of purpose. This indicates that energy flow may also be regarded as immaterial, e.g. based on a desire to be loved, on pursuit of values, or on living for a spiritual purpose. Investigation of the material and immaterial double nature of human energy flow may help to better understand the health of a person.

The entire life is an evolutionary process. Biologically human life originates with the fertilization of an oocyte. This then passes through the stages of embryo and foetus to the maturity needed for birth. At some time during intrauterine life the personality of the individual is created. At the least, physicians and midwifes say that in the new-born it is clearly recognizable. From then on the complete Meikirch model is fully operational during all phases of the life course of each person. Thus evolution from birth to death demonstrates clearly how many adaptive processes occur as part of the different complex interactions described by the model. While the two potentials evolve, the demands of life, the social, and the environmental determinants also vary. Within these limiting and supporting contexts individuals follow an autonomously chosen life course. Under such conditions it is not surprizing that some adaptations may not be fully successful for some time or permanently. Challenging examples are malnutrition, infectious diseases, love deprivation, sexual maturation, pregnancy, genetic defects, professional stress, the raising of children, physical involution, aging, etc. Such changes may lead an individual as a system into a state of crisis. If it is minor, the two potentials still may manage the demands of life and the difficulties may resolve spontaneously after some time. Such situations are not considered to represent a disease. Yet, they may evolve into a chronic state that draws energy from the person and thereby may explain e.g. insomnia, chronic fatigue, or somatoform symptoms. If the defect gets more severe it may lead to a disease that requires more medical attention. In the Meikirch model the term disease implies that for any reason one or several adaptation processes are not successful enough to empower the two potentials to satisfy the demands of life.

\section{Methods}

Consequences of the Meikirch model and of the properties of CASs are explored with the purpose to better understand the state of health of patients, particularly in internal medicine and general practice. The individual as a patient, according to the Meikirch model, is considered to be a nested CAS, composed of grouped CASs and being embedded in higher CASs. For this purpose, the significance of each of the five components and of each interaction within the Meikirch model must be visualized. In addition, possibilities to support favourable evolutions of the respective CAS and its meaning for the whole person (nested CAS) were studied. In this process, the deduction and induction cycles were repeated until coherent results were received.

\section{Results}

Categories of illness and disease

Disturbances in health and healing follow a pattern that can be described by four categories:

1. Minor maladaptations lead either immediately or with varying delays to discomfort (illness) or to signs of a disease. Examples for the former are minor acute infections or tension headaches, and for the latter, overweight, type 2 diabetes, or arterial hypertension.

2. A more relevant disturbance of the system leads it into a crisis, i.e. it becomes "chaotic". Such states may e.g. be corrected spontaneously, or by behavioural changes, or by interacting with a physician or healer, by medications, or by operations. Thereafter there may not be an immediate complete recovery to health. The full adaptive evolution may take time and further interventions that are called convalescence or rehabilitation may be needed. These phenomena may lead to complete healing or to healing with defects.

3. If a CAS is disturbed continuously for a prolonged time, the CAS apparently is not able to satisfactorily respond to the demands of life. This represents a chronic disease or invalidity. If the condition is progressive and serious, it may lead to death. Examples are rheumatic or degenerative diseases and different types of neoplasms.

4. Considering a disturbed state of health as a maladapted CAS implies that patients cannot simply be healed by the actions of a competent physician. Healing much rather is the result of a process of self-reorganization, enabling the two potentials to again satisfactorily fulfil the demands of life. The task of physicians and other health professionals therefore consists in being competent advisors and fellow human beings that assist the patient to realize the necessary evolution himself.

\section{Assessment of the health of a patient}

Initially it is appropriate to examine a patient with an ordinary medical history and physical examination to which all indicated laboratory tests and imaging procedures are added. When this does not lead to a satisfactory and clear result, it may be purposeful to perform an analysis of the patient's health as a CAS. In this case the five components and the ten complex interactions of the Meikirch model are assessed by an extended history as exemplified in Box 3. A thorough analysis will give the patient a new way to look at his health and how he has led his life. He will discover aspects he did not think about before, and this may be of therapeutic value. At the same time the physician may start to interpret the patient's history and findings in a new way. He may discover further possibilities for helping the patient to autonomously evolve to a new state which hopefully comes closer to health. 


\section{Box 3. Assessment of a patient's health by taking a history focussing on all aspects of the Meikirch model}

In addition to the five components and the ten complex interactions also the energy flow and other patterns of the model need to be investigated. The questions enumerated are just examples that have to be adapted and complemented further as needed for each patient's specific problems.

\section{Questions related to the components of the model (a-e):}

a) Which specifically are the demands of life to which the patient has to respond?

b) How does the patient appreciate the evolution of his physical health?

c) How does the patient feel about himself? Can he manage himself? Does he invest in his future?

d) How is the patient integrated into family, household, friends, society and government?

e) In which type of natural environment is the patient living?

\section{Questions about the interactions (1-10)}

1. How does the physical body of the patient (past and current) interact with his demands of life?

2. How does the patient deal with his physical, psychological and spiritual demands of life?

3. How does the patient interact with himself, especially with his body? Does he invest in it?

4. How does the patient interact with family, household, friends, and government etc.?

5. How does the physical body of the patient interact with the society? (past, present, future)

6. How does the society influence the demands of life?

7. What tis the attitude of the patient toward his natural environment?

8. Which are the past, present and future interactions of the natural environment with the patient's physical body?

9. How does the natural environment modify his demands of life?

10. How does the society interact with his natural environment?

\section{Questions about vitality, motivation and purpose in life}

- What is the source of the patient's vitality? Is it spontaneous or rather focused on objectives or purposes? Which occasions induce which type of vigour? What is his purpose in life?

- How is the patient's physical, intellectual, and emotional vitality? How much is hedonistic and how much eudaimonic?

- What does the patient do with his vitality? Is it used mostly in family, profession, or hobbies?

- How is the energy flow between the patient and his physician?

\section{Questions about temporal patterns}

- When did the patient feel completely healthy the last time? When and how did he loose his health or wellbeing?

- What were the manifestations of the crisis?

- How was the time course of the disease up to now? Which factors induced aggravation and which improvements? Which changes within or outside the patient induced which type of changes?

- What is the explanation of the patient for his current state of health and for his failure to improve it? What does the patient need in order to get over the present crisis?

- What are the future plans of the patient? How much sense of purpose do they give him?

\section{Treatment}

Obviously for all medically diagnosed conditions treatments are to be prescribed as indicated. Yet, in medicine, indications generally leave much room for judgements. Therefore the findings collected by assessing all components and interactions of the Meikirch model must be considered and integrated as much as possible. A CAS cannot be manipulated to health. It must be assisted to reorganize itself autonomously to a new state, in order to better fulfil the demands of life, hence better health and well-being. Therefore the role of the physician is to accompany the patient during the process he goes through. Some advice, assistance, or therapeutic intervention may be helpful, but only the patient is in a position to create his new future state for himself. By analysing his condition as a CAS together with his physician including all components and all interactions of the model he presumably receives many new ideas that he can use to emerge to a healthier state in the future. For example, he may want to make up his mind whether or not he will accept all the conditions that have determined his life in the past. In this respect, a discussion with his physician of alternatives with their consequences may be useful. For many patients it might be constructive to deal with the energy flow in their system, e.g. to speak about the purpose of their lives. 
The process of reorientation based on the Meikirch model will take time. During this period it may help the patient, if he finds in his physician a trustful human being with whom he can discuss all sorts of alternatives. Ultimately though, patients have to create their own future. It will encourage them, if they feel understood, trusted and accompanied by an experienced person with a sincere interest in their wellbeing.

\section{When is attention to the Meikirch model and the principles} of a CAS indicated?

In internal medicine and general practice there are many patients who come for consultations because they feel ill. Yet, on examination no clear pathology is found. So far such complaints are explained as functional and often are degraded by physicians as unimportant. Patients then receive drugs that may be symptomatically beneficial or placebos, more often than not harmful or noceboes. Instead of acting with benign neglect, the Meikirch model offers a true and positive alternative approach. In many cases it will help the patient to understand his problems, to readjust his potentials and to advance his readaptation to the demands of life. Thereby patients may again come closer to a state of health and wellbeing.

\section{Discussion}

At the present time the Meikirch model is a hypothesis grounded on a theoretical framework. Yet, until now much of health care has not been concerned with an understanding of the nature of health; it used instead an intuitive notion of wellbeing which did not lead to new insights. In contrast, a rational understanding of health as given by the Meikirch model - offers innovative opportunities. Today this model is better founded on scientific evidence than other definitions of health. Its ultimate validity, however, will be documented only by using it in practice. This must be done with due consideration to the special features of the model. Much further research is urgently needed.

For the past 150 years medicine has been working with methods derived from Newtonian natural science and obviously has achieved major advances. They are based, however, predominantly on materialism and neglect the social and spiritual features of the human nature. In addition, until recently medicine has not considered systems theory. It appears that these two aspects offer new opportunities for health care to become even more effective. Systems thinking implies that science based on Newton must be complemented by complexity science. Particularly for the purpose of health care a phenomenological, narrative, evolutionary holism must be added to analytical reductionism ${ }^{11}$. Poorly functioning parts are not simply corrected by appropriate drugs or surgical operations. Instead considerations of the evolution of the patient's health to the present state, earlier successes in self-management and failures in the handling of his present crises can be evaluated. Antonovsky's sense of coherence and meaningfulness also may be very helpful ${ }^{12}$. Necessary changes a patient has to realize must not come top-down from the physician, but rather bottom-up, originating in the patient himself, e.g. by new insights. For this purpose mutually trusting patient-physician interactions are critical for a successful future: the physician must believe in the patient's abilities to evolve to a new state and must accompany and support him with loving wisdom in this endeavour.
When speaking with older and experienced general practitioners, and when reading about how they managed their difficult patients, it becomes evident, that they knew their patients from the past quite well. In many difficult situations they often had to accompany rather than to treat them. Such patients remained very loyal because they understood what their doctor had contributed to their health. At the same time physicians realized that they had nothing more to offer than their personal support as a professional human being. The Meikirch model offers now a rational approach to such difficult cases and it is hoped that it will give new opportunities for patients to move toward better health. At the first glance the described system's approach to patient care is similar to what Michael Balint intended with his groups ${ }^{13}$. He was psychiatrist and pursued the purpose to train general practitioners in psychotherapy. In contrast, the systems theory focusses on a new look at a patient's possible unresolved evolutionary steps, analyses the biological given and personally acquired potentials and offers him an opportunity to progress further in his personal biography. More research is needed to validate the promises and limitations of this approach.

The Meikirch model distinguishes two types of very different potentials with which the demands of life must be met, the biologically given potential (BGP) and the personally acquired potential (PAP). The latter is the resource that continuously pilots the adjustment to new life situations. It is the locus of executive functions ${ }^{14}$. For this purpose it interacts with all components of the system. The PAP is the seat of memory, visions, fantasy, reasoning, attentional control and inhibitory control, and problem solving. Its sustained evolution toward more and more wisdom is critical for the maintenance of health. The PAP can learn to compensate in part for losses of the BGP. This leads to an interesting aspect of the relationship between the two potentials. It may be compared to rider and horse. If the rider wants that his horse serves him well he has to take good care of his horse. It appears that the neglect of the PAP in modern medicine is well perceived by patients. Therefore they turn to complementary or alternative medicine. In fact, much of the success of homeopathy and other methods might be explained by the physician patient interaction with its effects on the complex adaptive system that expresses the patient's health. This mechanism may be relevant also for much of the success of other complementary or alternative treatments. It is our opinion, however, that it will be better to work with the CAS in a planned and scientifically justifiable manner based on the Meikirch model than to apply unproven methods. The model would also serve as an excellent framework for a proper practice of evidence based medicine as defined by David L. Sackett: "Evidence-based medicine $(\mathrm{EBM})$ requires the integration of the best research evidence with our clinical expertise and our patient's unique values and circumstances ${ }^{15}$." This applies also to the newly evolving holistic clinical approach "Integrative Medicine and Health" that "reaffirms the importance of the relationship between practitioner and patient, focuses on the whole person, is informed by evidence, and makes use of all appropriate therapeutic and lifestyle approaches, healthcare professionals and disciplines to achieve optimal health" ${ }^{16}$.

When looking at health as a lifelong and complex evolutionary process, it is not surprising that crises do occur frequently. Throughout human life there are several major and many minor evolutionary steps to be taken. End of breastfeeding, beginning 
of school, puberty, professional formation and advancement, partnership, family, menopause, and involution of old age are some of the more demanding processes. Today they must be overcome in a society that offers insufficient respect for the personality of each individual. Lack of a motivating purpose in life and insufficient social support have become almost normal. Economic exploitation, power plays, isolation, social neglect and even wars weigh heavy on the demands of life. A culture that is really concerned with the health and wellbeing of its individuals needs to strongly support lifelong human development by investing in life-affirming compassion and truth ${ }^{5}$. The Meikirch model gives a framework for how this could be achieved.

\section{Author contributions}

Both authors contributed to drafting the work, were involved in the revision of the draft manuscript and have agreed to the final content.

\section{Competing interests}

No competing interests were disclosed.

\section{Grant information}

The author(s) declared that no grants were involved in supporting this work.
1. Virchow R: Die Cellularpathologie in ihrer Begründung auf physiologische und pathologische Gewebelehre. Berlin: Hirschwald, 1858. Reference Source

2. Lorenz E: The Essence of Chaos. Edward Lorenz: Seattle, 1993; Appendix 1: S181-184. Reference Source

3. Sturmberg JP, Martin CM, Katerndahl DA: Systems and complexity thinking in the general practice literature: An integrative, historical narrative review. Ann Fam Med. 2014; 12(1): 66-74. PubMed Abstract | Publisher Full Text | Free Full Text

4. Bircher J, Kuruvilla S: Defining health by addressing individual, social, and environmental determinants: new opportunities for health care and public health. J Public Health Policy. 2014; 35(3): 363-86. PubMed Abstract | Publisher Full Text | Free Full Text

5. Bircher J, Hahn EG: Understanding the nature of health: New perspectives for medicine and public health. Improved wellbeing at lower costs [version 1; referees: 2 approved]. F1000Res. 2016; 5: 167. PubMed Abstract | Publisher Full Text | Free Full Text

6. Maklem PT, Seely A: Towards a definition of life. Perspect Biol Med. 2010; 53(3) 330-40.

PubMed Abstract | Publisher Full Text

7. Wilkinson R, Pickett K: The Spirit Level: Why Equality is Better for Everyone. London: Penguin Books, 2009 Reference Source

8. Marmot M, Wilkinson RG: Social Determinants of Health. 2nd edition, Oxford
University Press, 2005

Reference Source

9. Brundtland GH: Report of the World Commission on Environment and Development: Our Common Future. 1987.

Reference Source

10. Watts $\mathrm{N}$, Adger WN, Agnolucci $\mathrm{P}$, et al.: Health and climate change: policy responses to protect public health. Lancet. 2015; 386(10006): 1861-914. PubMed Abstract | Publisher Full Text

11. Lansing JS: Complex Adaptive Systems. Annu Rev Anthr. 2003; 32: 183-204. Publisher Full Text

12. Antonovsky A: Unraveling the mystery of health - How people manage stress and stay well. Jossey-Bass Publishers, San Francisco, 1987. Reference Source

13. Balint M: Training general practitioners in psychotherapy. Br Med J. 1954 1(4854): 115-20. PubMed Abstract | Free Full Text

14. Diamond A: Executive functions. Annu Rev Psychol. 2013; 64: 135-68. PubMed Abstract | Publisher Full Text | Free Full Text

15. Straus SE, Richardson WS, Galsziou P, et al: Evidence-Based Medicine: How to Practice and Teach it. 4th edition, Churchill Livingstone-Elsevier, Edinburgh, 2010. Reference Source

16. Academic Consortium for Integrative Medicine \& Health (The Consortium): Advancing integrative medicine and health through academic institutions and health systems. Reference Source 


\section{Open Peer Review}

\section{Current Peer Review Status:}

\section{Version 1}

Reviewer Report 05 August 2016

https://doi.org/10.5256/f1000research.9730.r15463

(C) 2016 Delva D. This is an open access peer review report distributed under the terms of the Creative Commons Attribution License, which permits unrestricted use, distribution, and reproduction in any medium, provided the original work is properly cited.

\section{Dianne Delva}

Department of Family Medicine, Faculty of Medicine, University of Ottawa, Ottawa, ON, Canada

This is an article describing the confluence of two theories, the model of health as defined by the authors in the Meikirch model which appears to be a model developed and published by the authors, and complex adaptive systems. The authors propose this as a method to better help patients adapt and aim towards improved health.

\section{Strengths:}

The authors have developed a theory and are proposing this explicit theory can better support patient care. Primary care is known for its complexity and uncertainty. Thus the system is a good framework for thinking about a holistic approach to patient care and to the variability of adaptation based on the components. The categories of illness and disease would be helpful for learners to understand that not all illness has a desired resolution. The comments on complex adaptive systems as a way of understanding health in individuals and society is useful in reminding us that linear models often ignore the unintended consequences of change.

\section{Suggestions:}

As a family physician, I found the paper both interesting and difficult to follow. In general the language is clear with minor errors. I am not an expert on complex adaptive systems but agree with the comment regarding the use of some terms as detracting from the premise of the article. My main suggestion would be to expand the methods section. It is not clear to me who was involved in the process, how this was carried out. I wonder if this would be better as a theoretical proposal rather than a scientific study. The examples chosen seem to be the opinions of the authors and have not been tested. Some are quite vague and would require fuller explanation.

I also agree that comparing this theory to others might be useful. McWhinney is referenced and as a leader in Family Medicine in Canada, the four principles of family medicine and a model we use to teach residents for patient-centered care helps us to provide care in family medicine that is not likely to be enhanced by the model. The four principles are: 
The family physician is a skilled clinician.

Family medicine is a community-based discipline.

The family physician is a resource to a defined practice population.

The patient-physician relationship is central to the role of the family physician.

It may be that the authors are specialists and thus are less familiar with general/family practice. The idea that "Physicians then examine them and specifically look for pathological changes." is not the premise for family medicine in Canada. The four principles address the environment and social determinants of health in situating the patient in the community and family in which they live. The idea of accompanying the patient resides in the value of continuity of care and the patient-physician relationship. Knowing the patient's values and past helps to tailor the approach to support the patient in the direction they wish to go. The skilled clinician is a critical thinker who can deal with uncertainty and as a resource to the practice population advocates for the system to better serve the population.

In Canada we teach a model of interviewing that includes the traditional history focused on disease interwoven with the IFFE model. These include the patient's ideas of what is wrong with them, their fears, how their function is affected and their expectations from the physician/system. These questions are essential to the patient-centered approach and situate the consultation clearly with the patient as the CAS.

In particular, I find the suggestions for taking a history based on the model cumbersome and clearly the language would be challenging for patients. It is also not clear to me how these questions are related to the CAS.

The treatment approach mirrors the patient-centered approach taken in family medicine. We know that patients often do not fill prescriptions and asking patients what might work for them or what they are comfortable with, helps one to support a treatment approach that is right for the particular patient. Being aware that a patient does not have the resources to access a particular treatment is essential to a collaborative effort for care.

Some of the examples either require more explanation or less linear thinking. The idea that in utero does not include the environment overlooks the social determinants of health of the mother and their effect on the in utero environment.

I have been involved in a number of Balint groups and recall reading Michael Balint's book. The statement "He was psychiatrist and pursued the purpose to train general practitioners in psychotherapy." does not reflect my experience. My understanding was he focused on Difficult Clinician-patient relationships to help general practitioners interact and "accompany" our patients more effectively. The groups were meant to support physicians in their own context. I did not see this as training in psychotherapy.

\section{Minor suggestions}

"Examples of medical conditions are ventricular fibrillation, epileptic seizures, tantrum, or psychotic states." This statement needs further explanation. It is not logical from the discussion if we think of health in a holistic manner. 
There may be cultural differences in writing and I appreciate English may not be the first language of the authors; however I find it a poor reflection to refer to all patients and physicians as male.

Competing Interests: No competing interests were disclosed.

\section{I confirm that I have read this submission and believe that I have an appropriate level of expertise to confirm that it is of an acceptable scientific standard, however I have significant reservations, as outlined above.}

Author Response 19 Sep 2016

Eckhart G. Hahn, University Hospital Erlangen, Erlangen, Germany

\section{Response to the comments by Dr. Dianne Delva}

We as authors appreciate the care Dr. Delva has devoted to our paper. It has helped us significantly to improve the manuscript and make it readable for family physicians. Also, we are happy that she recognizes the overall strengths of our contribution. We understand that she appreciated the value of thinking in terms of health and disease as complex adaptive systems (CAS) to embrace uncertainty and a holistic approach to patient care. In order to respond to her concerns with some aspects of our manuscript we would offer the following point by point response. We will also indicate where we have made changes and corrections of the manuscript.

1. From Dr. Delva's critical comments as a family physician we have come to the conclusion that the original title does not completely reflect the content of the paper and may be misinterpreted. We do not intend to challenge any of the established models as applied to family medicine. We rather intended to explore the possible results of applying the principles of complex adaptive system's thinking in primary patient care, possibly extending the present practice. Therefore, to avoid any misunderstanding, we have changed the title of the paper into "Applying a complex adaptive system's understanding of health to primary care". This was also suggested in the review of Dr. Sturmberg (accessible under http://f1000research.com/articles/51672/v1).

2. Interestingly, Dr. Delva refers to Dr. I. R. McWhinney, who had developed four principles for family medicine. He certainly is an important person for the principles of family medicine. These principles refer to the physician as a skilled clinician, to family medicine as a community based discipline, to family physicians as resource to a defined population, and view the patient-physician interaction as central. Interestingly these four postulates are also part of the Meikirch model. Also the proposals of the so called Wonca-tree are included in the model. The Meikirch Model is wider than the specific concepts for family medicine and therefore might in the future serve as an extended basis on which the others stand: this is what we suggest to explore.

3. We agree with Dr. Delva that the physician must value the continuity of care and be competent to deal with uncertainty. We, as proposed in the Meikirch model, have a different view how the patient should be supported, derived from the thinking of health and disease as a complex adaptive system. As a CAS, the patient's situation 
evolves independently and autonomously, often against his or her will. The support in our opinion has the purpose to help the patient to move to his new state that results in a more satisfactory emergence. Often the route to this new state is not the "direction the patient wants to go", but the direction to which the patient has to submit himself. That is why he needs the physicians support.

4. On page 4, an effort has been made to further clarify what a CAS means and what it may contribute to the primary care of patients. In figure 2 the term "attractor" was removed because it is not essential to understand the principle of a CAS.

5. On pages 5 and 6, the method section has been expanded as suggested by Dr. Delva. Both authors have contributed to the development and description of hypothetical consequences of the Meikirch model to stimulate future research. One of the authors $(E G H)$ is trained in and practiced general internal medicine (and gastroenterology) and is familiar with Robert Nikolaus Braun's conceptual frame of family medicine which is prevalent in German speaking countries.

6. In a participatory and integrative approach to the patient, the inclusion of the patient's ideas, fears, functions and expectations (IFFE model) is indeed essential for any primary encounter between patient and physician. It is also part of the Meikirch model, as can be seen in box 3 on page 6 . Dr. Delva finds it cumbersome to take a history based on the Meikirch model and states that it is not clear to her how the questions in box 3 are related to the CAS. Obviously this table contains examples, is not exclusive and must be adjusted to the patient's specific problems. The purpose of box 3 is to give the physician a tool to make sure that the history he took covers the whole Meikirch model, i.e. is complete in this sense. The questions suggested in box 3 , derived from the Meikirch model with its complex interactions, will also be the basis for describing the patient as a CAS. The Meikirch model is in itself based on complex adaptive systems thinking. Dr. Delva, is right in suggesting to use plain language in real life communication with patients.

7. In order to clarify the issue of the situation in utero we believe that the direct environment of a fetus is the uterus of the mother. The environmental and social determinants of the mother have nonetheless an indirect effect on the child's development in utero as has been pointed out in a previous description of the Meikirch model.

8. Dr. Delva refers to her understanding of Balint groups. We have taken the information given in our paper directly from an original publication by Michael Balint (1896-1970) in the Br Med 1954 (see reference 13). Balint groups may have developed in a direction not intended by Balint himself, and we agree that the term psychotherapy is not well defined and can be understood in many ways in Balint's original paper. The case reports included in this paper describe complex psychodynamic situations. We have changed our text on page 9 to stay as close to Balint's original paper as possible.

9. The butterfly effect used as a metaphore on page 4 is now described in more detail to assure a better understanding of our mentioning of ventricular fibrillation, epileptic seizures, tantrum or psychotic states. These conditions, because of their dramatic appearance, are exclusively meant as an illustration of the butterfly effect.

10. Wherever the gender-neutral terms "patient" or "physician" were used in our text we have now avoided to use them in a gender-specific context by either omitting "he" or "she" or using the plural, including in the abstract. 
Fink, W. \& Kamenski, G. Wien Med Wochenschr (2009) 159: 173. doi:10.1007/s10354-0090666-8

Bircher J, Hahn EG: Understanding the nature of health: New perspectives for medicine and public health.

Improved wellbeing at lower costs [version 1; referees: 2 approved]. F1000Res. 2016;5:167. 27134730

10.12688/f1000research.7849.1 4837984. See page 4 „personally aquired potential“.

Competing Interests: No competing interests were disclosed.

Reviewer Report 25 July 2016

https://doi.org/10.5256/f1000research.9730.r15187

(C) 2016 Sturmberg J. This is an open access peer review report distributed under the terms of the Creative Commons Attribution License, which permits unrestricted use, distribution, and reproduction in any medium, provided the original work is properly cited.

\section{Joachim P Sturmberg}

Department of General Practice, University of Newcastle, Wamberal, NSW, Australia

This paper is an extension of the authors' previous paper in this journal and stimulates long overdue debate. My previous comments ${ }^{1}$ principally also apply to this paper.

Two additional points:

1. The paper's title "Health as a Complex Adaptive System: a new dimension of patient care in internal medicine and general practice" only loosely reflects the content of the paper, I would think that a title similar to "Applying a complex adaptive system's understanding of health to clinical care" would be stronger and more appropriate. Offering clinicians alternative ways of practicing is certainly most welcome.

2. The paper - implicitly - wrestles to come to terms with the notions of health in relation to the "non-health" terms of illness and disease ${ }^{2}$. Even definable pathology is not objective as many studies have shown significant disagreement between experienced clinicians looking at the same "example of disease". Highlighting the definitional problems and distinctions is especially important for primary care physicians as many people present with unspecific symptoms rather than a "specific diagnosis" ${ }^{3}$. Diagnoses are socially constructed ${ }^{4}$ and have become a "tyranny for clinicians" ${ }^{5}$. From a complexity perspective thinking about patients' complaints as "conditions" or "states of being" clearly fosters more creative approaches to patient care and the emergence of more satisfactory outcomes. 


\section{References}

1. Sturmberg J: Referee Report For: Understanding the nature of health: New perspectives for medicine and public health. Improved wellbeing at lower costs [version 1; referees: 2 approved]. F1000Research. 2016; 5 (167). Publisher Full Text

2. Lewis S: Exploring the Biological Meaning of Disease and Health. last accessed 24th June 2016. 2003. Reference Source

3. Sturmberg JP, Martin CM: Diagnosis - the limiting focus of taxonomy.J Eval Clin Pract. 2014. PubMed Abstract | Publisher Full Text

4. Rosenberg CE: The tyranny of diagnosis: specific entities and individual experience.Milbank Q. 2002; 80 (2): 237-60 PubMed Abstract

5. Konitzer M, Fink W, Lipatov V, Kamenski G, et al.: Coping with Complexity and Uncertainty: Insights from Studying Epidemiology in Family Medicine. In: Sturmberg JP (ed) The Value of Systems and Complexity Sciences for Healthcare, Springer International Publishing, Switzerland. 2016. Publisher Full Text | Reference Source

Competing Interests: No competing interests were disclosed.

I confirm that I have read this submission and believe that I have an appropriate level of expertise to confirm that it is of an acceptable scientific standard.

\section{Comments on this article}

\section{Version 1}

\section{Author Response 19 Jul 2016}

Eckhart G. Hahn, University Hospital Erlangen, Erlangen, Germany

We chose F1000Research for publication of our paper, because with the comment section this journal invites a scientific discourse on the subject. David C Norris MD, however, uses the first paragraph of his comment for a personal attack on the authors. This has nothing to do with a scientific discourse and therefore cannot be answered by scientific arguments. Johannes Bircher and Eckhart G. Hahn.

Competing Interests: Johannes Bircher and Eckhart G. Hahn are the authors of the article.

Reader Comment 18 Jul 2016

David C. Norris, Precision Methodologies, LLC, USA

This paper is written in such a way no serious reviewer could afford to drop his or her guard against the possibility of a phenomenon like the Sokal affair. That said by way of self-protection, I will proceed on the assumption that the humanistic impulses evident in this piece reflect a sincere desire to broaden perspectives on human health and to encourage medical care that aims at such 
a broader vision. I can attest that this is sorely needed in my own country, and this BMJ essay by Emma Lewis corroborates my suspicion that this applies anywhere Medicine yields to centralized bureaucratic controls.

The authors could make this effort more credible by employing language and concepts drawn from the physical and complexity sciences only inasmuch and insofar as these demonstrably contribute to the clarity and intellectual content of the claims made here. The biggest red flag in this respect is Figure 2, where entropy is shown flowing across a system boundary from a system to its environment. Unless the authors are prepared to discuss the notion of temperature of a CAS, and to employ an energy concept in a critical and uniform fashion, then they might do well to abandon the language of thermodynamics altogether. In their gratuitous usage here, words like 'entropy', 'energy', 'work', 'attractor' seem little more than attempts to arrogate the authority of the well-organized fields of thermodynamics and dynamical systems theory to a decidedly unsystematic accretion of fanciful notions about health.

Methodologically, the authors might proceed to develop their notions into a coherent system of thought by proceeding along one or more of the following lines:

- Attempt a critical evaluation of the Meikirch model as a scientific theory, from which testable predictions can be derived. Surely, there are normative elements in any such theory, but these could be made explicit, and demarcated clearly from whatever scientific content the Meikirch model possesses.

- Present one or more case studies demonstrating the utility of the Meikirch model in the care of an individual patient. Evidence could be offered, as is customary, in the words of the patient. These words could demonstrate perhaps the organic 'emergence' of new understanding within the patient, utilizing whatever conceptual tools remain in the Meikirch model after it is purged of pseudoscientific terminology.

- Undertake a comparative analysis of several distinct approaches to developing broader notions of health and the aims of medical care. Consider serious work in this area by other researchers. Examine how that work demonstrates inadequacies in the Meikirch model, and vice versa as appropriate. If nothing else, such comparative analysis would help to illuminate what the actual content of the Meikirch model is.

I do not think it would reflect well on F1000Research as a science journal to accept this article in its present form.

Competing Interests: I declare no competing interests. 
The benefits of publishing with F1000Research:

- Your article is published within days, with no editorial bias

- You can publish traditional articles, null/negative results, case reports, data notes and more

- The peer review process is transparent and collaborative

- Your article is indexed in PubMed after passing peer review

- Dedicated customer support at every stage

For pre-submission enquiries, contact research@f1000.com 